\title{
Social media use for travel purposes: a cross cultural comparison between Portugal and the UK
}

\author{
Suzanne Amaro' ${ }^{1}$ Paulo Duarte ${ }^{2}$ (D)
}

Received: 15 June 2016/Revised: 29 December 2016/ Accepted: 20 January 2017

(C) Springer-Verlag Berlin Heidelberg 2017

\begin{abstract}
Social media plays an important role in travelers' planning and decisionmaking. Research has highlighted that the use of social media on travel planning may differ among countries, whereas culture may explain those differences. This article explores the use of social media for travel and compares United Kingdom and Portuguese citizens based on Hofstede's cultural dimensions. Results revealed that travelers from both countries use social media essentially before travelling yet, some differences were found regarding the use after traveling and between social media consumption and creation. Travel marketers can use this knowledge to adapt social media strategies to country specific situations.
\end{abstract}

Keywords Cross Cultural · Social Media · Tourism \&Travel · Hofstede · Cultural dimensions

\section{Introduction}

As many other products and services, travelers need to search for information to make decisions, such as which destination, airline company or hotel to choose (Jeng and Fesenmaier 2002; Chung and Buhalis 2008a). More, compared to other services or products, travel normally requires more information processing before making a decision, because the purchase of travel products is considered to be highly risky (Huang et al. 2010). Indeed, to consume tourism products, individuals must leave

Paulo Duarte

pduarte@ubi.pt

Suzanne Amaro

samaro@dgest.estv.ipv.pt

1 Polytechnic Institute of Viseu, Campus Politécnico, 3504-510 Viseu, Portugal

2 Management and Economics Department, Faculty of Human and Social Sciences, University of Beira Interior, Edifício Ernesto Cruz, Estrada do Sineiro, 6200 Covilhã, Portugal 
their daily environment and move to a geographical different (Werthner and Ricci 2004) and when making travel decisions, only descriptions are available (Werthner and Klein 1999). On the other hand, consumers cannot try travel products/services before purchasing, making it difficult to evaluate the value for money before the actual experience (Kim et al. 2009). In this context, information search decreases uncertainty associated with travel, enhancing the quality of tourists' trips (Fodness and Murray 1997).

Given these characteristics, the popularity of the Internet to search for travel related information in not surprising. Indeed, the Internet is the number one source of information in trip planning (Xiang et al. 2015). In particular, travel related social media websites have gained popularity not only for travelers' search for information (Xiang and Gretzel 2010) but also to post information regarding their trips, through comments, photos or pictures (Parra-López et al. 2012). Kaplan and Haenlein (2010, p. 61) define social media as "a group of Internet-based applications that build on the ideological and technological foundations of Web 2.0, and that allow the creation and exchange of user-generated content". Social media includes, among others, social networking sites, content community sites, wikis, Internet forums and location-based social media, and has emerged as the new way in which people connect socially, by integrating information, communication, social interaction, and the construction of words, pictures, videos and audio (Zeng and Gerritsen 2014). Zeng and Gerritsen (2014) literature review addressing social media in tourism stresses the significant role social media has in information search and decisionmaking behaviors. According to a recent study conducted by Xiang et al. (2015) "social media are having enormous impact on travel planning" (p.246). Indeed, in a recent study on travel trends, $73 \%$ of travelers indicated that TripAdvisor, the leading social media website for travel planning, was the most influent source when making their travel plans, ahead of word-of mouth (TripAdvisor 2015a). This finding is echoed in Deloitte (2015) study. Phocuswright (2015), one of the leading travel industry research firms, found that $82 \%$ of US travelers and $80 \%$ of British are active on social media networks, mainly to post while traveling and look for deals.

Given the increasing usage of social media for travel purposes, literature on this matter has been increasing. Popular topics have been travelers' motivation to use social media (Chung and Buhalis 2008b; Parra-López et al. 2012) and the impact of social media on travel decisions (Chung and Buhalis 2008b; Sparks and Browning 2011; Yoo and Gretzel 2012). More recently, literature reviews on social media in tourism and hospitality have been published (Leung et al. 2013; Zeng and Gerritsen 2014).

Although an increasing body of published literature focusing on cultural differences in social media use is emerging (e.g. Jackson and Wang 2013), cross cultural studies addressing social media in the travel context are still scarce. Nevertheless, several studies show that social media has a significant impact on consumer choice in tourism (e.g. Sparks and Browning 2011; Jacobsen and Munar 2012; Litvin and Hoffman 2012; Pietro et al. 2012). On the other hand, the utility of social media in tourism greatly depends on the perception people have on social media credibility (Tham et al. 2013). Since national culture shapes human behavior (Ayeh et al. 2016), it is important to understand if differences in culture could 
influence how tourists use and value social media for travel purposes. Tourism's international nature should generate more attention for cross-cultural research (Dimanche 1994) in order to demonstrate the power of cultural dimension on tourist behavior and choice. To the best of knowledge, until now, only one study has examined the impact of national culture on travelers' social media use that used a qualitative approach based on secondary data (Gretzel et al. 2008). More recently Gretzel et al. (2011) suggested carrying out empirical research to examine the differences regarding the creation of travel related content between different countries. Despite all these evidences there is a lack of investigation exploring how cultural differences explicitly affect the production, participation and consumption of travel related information in social media (Ngai et al. 2015). Yet, cross cultural research is crucial to adjust online marketing strategies to country specific situations in order to increase its effectiveness (Pookulangara and Koesler 2011). For example, it is anticipated that individuals from collectivist cultures will be more likely to use social media, by consuming and creating travel related information.

Expanding the limited knowledge on the influence of culture on social media usage in travel, this paper contributes to tourism literature by comparing the use of social media for travel purposes between two countries, Portugal and the UK. Further, since past studies have evidenced that national culture influences tourist behavior and the way they search for travel information (Pizam and Jeong 1996; Gursoy and Umbreit 2004; Ayeh et al. 2016) the present study shows how the cultural dimensions could affect the use of social for travel purposes not only before travel, but also when travel and after travel, providing researchers and practitioners with a better understanding of the process of consumption and creation of travel related content.

The purpose of this paper is to investigate the link between the cultural characteristics of the country and the use of social media for travel purposes based on Hofstede et al. (2010) cultural dimensions framework.

\section{Literature review}

\subsection{Social media in tourism and travel}

An important issue regarding the use of social media for travel purposes is examining the use of social media in all travel phases: Before, while and after travelling. Several studies have clearly evidenced that it is in the pre-travel stage that the use of social media is more extensive (Cox et al. 2009; Xiang et al. 2015; Öz 2015). In this stage, travelers use social media to find travel information regarding the destination, attractions, hotels, excursions and transportation (Cox et al. 2009; Fotis et al. 2012; Öz 2015). In this phase, travel reviews play an important role in the trip planning process by reducing risk and making it easier to imagine what places will be like (Gretzel and Yoo 2008). However, social media is also used during the trip, to search for travel related information on their holiday (Fotis et al. 2012). Due to the increasing use of smartphones and the higher availability of the 
Internet, an important trend will be travelers postponing some of the typical pretravel decisions to this stage (Xiang et al. 2015).

After the trip, travelers continue to use social media to share their travel experience through reviews and pictures (Fotis et al. 2012; Parra-López et al. 2012).

Travelers find motivation to use social media for travel purposes in the perceived functional (informational) benefits that social media provide (e.g. "social media tools enable me to keep up to date with the tourist sites" and "social media tools give me the possibility to exchange information about tourist sites") (Parra-López et al. 2012, p. 181). In fact, Chung and Buhalis (2008a) report that information acquisition was the most important factor influencing travelers to participate in online travel communities. However, other studies have shown that reading travel reviews added fun to the trip planning process, made travel planning more enjoyable and made travelers feel more excited about travelling (Gretzel et al. 2007; Gretzel and Yoo 2008). Chung and Buhalis (2008a, p. 76) found that users of online travel communities (e.g. Tripadvisor.com, VirtualTourist.com) participated in the online community activities not only for the informational benefits, but also for the hedonic benefits (i.e. "Having fun with contents", "Entertainment" and "To be amused by members"). In a different study, hedonic needs were pointed as an important predictor for the level of participation in an online travel community (Wang and Fesenmaier 2004). More recently, the positive relationship between the perceived hedonic benefits and motivation for using social media for travel purposes was confirmed by Ayeh et al. (2013). Focusing on the after trip phase, Yoo and Gretzel (2011) found that enjoyment is a driver of travel content generated media creation.

This empirical evidence demonstrates that individuals use travel related social media not only for information purposes but also because they consider its use enjoyable. Web 2.0 has made information search more personalized, active and interactive, which contributes to its hedonic value (Gretzel 2012).

Shao (2009) suggests that individuals deal with UGC in three ways: by consuming, by participating, and by producing. Consuming refers to the individuals who only read, or view but never participate. Participating includes both user-touser interaction and user-to-content interaction (such as ranking the content, adding to playlists, sharing with others, posting comments, etc.). Producing encompasses creation and publication of one's personal contents, such as text, images, audio, and video. Most travelers are just consumers or participators (Yoo and Gretzel 2011). Pan and Crotts (2012) report that travel blogs and social media sites have long recognized that there are far more people consuming information than generating it. Indeed, a study carried out by (Deloitte 2015) found that only $16 \%$ of the respondents had posted a travel experience online.

\subsection{Cultural dimensions and social media}

A considerable amount of cross cultural studies is grounded on Hofstede's cultural dimensions (Jackson and Wang 2013; Goodrich and De Mooij 2014; Ayeh et al. 2016). Indeed, this framework is considered to be the most comprehensive national cultural framework in cross-cultural studies (Litvin et al. 2004; Hsu et al. 2013) and can be used to explain and predict behaviors (Hofstede 1980). In 
Hofstede (1980) original work, country cultures were categorized into four groups according to: power distance (PDI), individualism versus collectivism (IDV), masculinity versus femininity (MAS), uncertainty avoidance (UAI). However, with the publication of Cultures and Organizations (Hofstede et al. 2010) two more dimensions were added: pragmatic versus normative (PRA) and indulgence versus restraint (IND). Table 1 lists these dimensions with a brief description of each dimension.

In the context of tourism and hospitality, Hofstede's cultural dimension scores are also widely used in cross-cultural studies (Li 2012). Some examples in this field include examining the influence of culture on tourist's behavior (e.g. Litvin et al. 2004), on consumer's evaluation of travel services (e.g. Crotts and Erdmann 2000)

Table 1 Cultural dimensions

\begin{tabular}{|c|c|}
\hline Dimension & Description \\
\hline Power distance & $\begin{array}{l}\text { Expresses the degree to which the less powerful members of a society accept } \\
\text { and expect that power is distributed unequally. People in societies } \\
\text { exhibiting a large degree of power distance accept a hierarchical order in } \\
\text { which everybody has a place and which needs no further justification. In } \\
\text { societies with low power distance, people strive to equalize the distribution } \\
\text { of power and demand justification for inequalities of power }\end{array}$ \\
\hline $\begin{array}{l}\text { Individualism versus } \\
\text { collectivism }\end{array}$ & $\begin{array}{l}\text { Preference for a loosely-knit social framework in which individuals are } \\
\text { expected to take care of only themselves and their immediate families. Its } \\
\text { opposite, collectivism, represents a preference for a tightly-knit framework } \\
\text { in society in which individuals can expect their relatives or members of a } \\
\text { particular in-group to look after them in exchange for unquestioning loyalty }\end{array}$ \\
\hline $\begin{array}{l}\text { Masculinity versus } \\
\text { femininity }\end{array}$ & $\begin{array}{l}\text { The masculinity side of this dimension represents a preference in society for } \\
\text { achievement, heroism, assertiveness and material rewards for success. } \\
\text { Society at large is more competitive. Its opposite, femininity, stands for a } \\
\text { preference for cooperation, modesty, caring for the weak and quality of life }\end{array}$ \\
\hline Uncertainty avoidance & $\begin{array}{l}\text { The uncertainty avoidance dimension expresses the degree to which the } \\
\text { members of a society feel uncomfortable with uncertainty and ambiguity. } \\
\text { The fundamental issue here is how a society deals with the fact that the } \\
\text { future can never be known: should we try to control the future or just let it } \\
\text { happen? Countries exhibiting strong UAI maintain rigid codes of belief and } \\
\text { behavior and are intolerant of unorthodox behavior and ideas. Weak UAI } \\
\text { societies maintain a more relaxed attitude in which practice counts more } \\
\text { than principles }\end{array}$ \\
\hline $\begin{array}{l}\text { Pragmatic versus } \\
\text { Normative }\end{array}$ & $\begin{array}{l}\text { In societies with a pragmatic orientation, most people don't have a need to } \\
\text { explain everything, as they believe that it is impossible to understand fully } \\
\text { the complexity of life. People believe that truth depends very much on } \\
\text { situation, context and time. They show an ability to adapt traditions easily } \\
\text { to changed conditions, a strong propensity to save and invest thriftiness and } \\
\text { perseverance in achieving results. In societies with a normative orientation } \\
\text { most people have a strong desire to explain as much as possible and have a } \\
\text { strong concern with establishing the absolute truth; they are normative in } \\
\text { their thinking }\end{array}$ \\
\hline $\begin{array}{l}\text { Indulgence versus } \\
\text { restraint }\end{array}$ & $\begin{array}{l}\text { Indulgence stands for a society that allows relatively free gratification of basic } \\
\text { and natural human drives related to enjoying life and having fun. Restraint } \\
\text { stands for a society that suppresses gratification of needs and regulates it by } \\
\text { means of strict social norms }\end{array}$ \\
\hline
\end{tabular}


and on student's travel preferences (e.g. Sakakida et al. 2004). All of these studies have supported that national culture influences individuals' behavior.

In Gretzel et al. (2008) study, the authors examined consumer generated media adoption in Germany, China, United Kingdom (UK) and the United States of America (USA). Their findings suggest that national culture is one of the factors that explain the different rates of adoption observed in these four countries. However, the study used a qualitative approach based on secondary data. The authors themselves call out for empirical research addressing this topic.

In a more recent study, although not specifically examining social media websites, Jordan et al. (2013) found that individuals from Belgium, a culture with high uncertainty avoidance, spent more effort in completing travel planning than Americans, a culture with low uncertainty avoidance. They explain these results by the fact that Belgians try to eliminate uncertainty related to trips with higher search efforts, concluding that the uncertainty avoidance cultural dimension affects how individuals search for travel information on the Internet. Also based on the uncertainty avoidance dimensions, Litvin et al. (2004) found that respondents with different scores exhibited different travel behaviors. For example, respondents from higher uncertainty avoidance cultures were more likely to acquire information from friends and relatives. Similarly, Quintal et al. (2010) findings indicated that uncertainty avoidance was related to the extent of travel information search.

Kim et al. (2011) and Ayeh et al. (2016) suggest that the Individualism versus Collectivism dimension may explain how individuals from different countries use social media. Indeed, individuals from a collectivist culture are more likely to use the Internet as mean of social communication as opposed to individuals from as individualist culture who tend to be more prone to informational benefits (Chau et al. 2002; Chu and Choi 2011; Ayeh et al. 2016). Moreover, in collectivist cultures, group values and the opinions of others are considered to be more important (Gretzel et al. 2008) and social media plays an important role in opinion formation (Goodrich and De Mooij 2014). According to the study by Lee and Gretzel (2014) there are significant differences between collectivist and individualist travel bloggers. For instance, collectivist blogs are more group focused and more other-directed in their structure, motivated to share their experiences to help others (Lee and Gretzel 2014). In contrast, individualistic cultures write about their travel experiences to register their own experience (Lee and Gretzel 2014). Pfeil et al. (2006) also found that individuals from collectivist cultures are more likely to add or clarify information on Wikipedia than individuals form individualist cultures. These findings seem to indicate the more caring values in collectivist countries.

\section{Research questions}

This exploratory research was conducted to contribute to the lack of cross cultural studies comparing the use of social media for travel purposes and to encourage further research to help assess the generalizability of the findings. Past studies have evidenced that national culture influences tourist behavior and the way they search for travel information (e.g. Pizam and Jeong 1996; Gursoy and Umbreit 2004). 
Therefore, based on the literature review carried out, several research questions were posited:

Research question 1 Do individuals from different cultures have different behavior regarding their use of social media for travel purposes before, during and after they travel?

Research question 2 Does the consumption of social media for travel purposes differ between individuals from different cultures?

Research question 3 Does the creation of online travel content differ between individuals from different cultures?

Research question 4 Does the perceived enjoyment of social media use for travel purposes differ between individuals from different cultures?

Research question 5 Does social media interest for travel purposes differ between individuals from different cultures?

\section{Methodology}

Similarly to other cross-cultural studies (e.g. Lee and Gretzel 2014; Sabiote-Ortiz et al. 2016; Choi et al. 2016) Portugal and the UK were selected for comparison as they represent reverse positions on most of the cultural dimensions, as shown in Fig. 1. Portugal is high in uncertainty and low in individualism, while in the UK it is the opposite. The UK also has much higher levels of masculinity than Portugal. Research addressing national culture comparisons typically include countries representing different levels of one or more cultural dimensions (Litvin et al. 2004). Thus, these countries were considered relevant for conducting a comparison to evaluate the influence of the cultural characteristics on social media use for travel purposes A similar procedure to select countries for cross-cultural research has been conducted in other studies (e.g. Kim et al. 2011; Jordan et al. 2013; Lee and Gretzel 2014). Several cross-cultural studies addressing technology adoption have selected

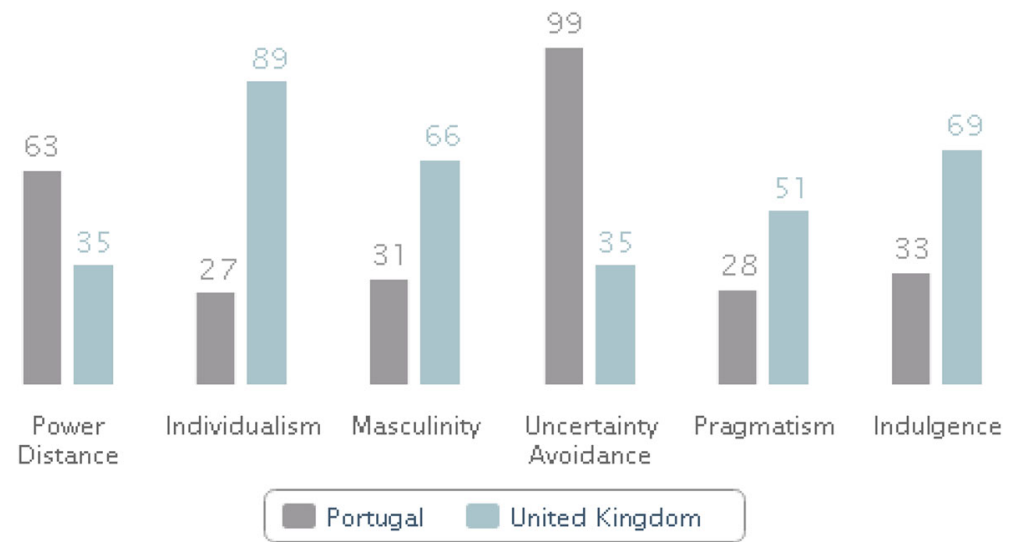

Fig. 1 Cultural index scores in Portugal and United Kingdom. Source http://geert-hofstede.com/. Accessed 3rd March 2015 
the UK, which is high in individualism and masculinity and low on uncertainty avoidance, to compare with countries with contrasting cultures, such as China (e.g. Li and Kirkup 2007; Michopoulou and Moisa 2016) and Hong Kong (e.g. Harris et al. 2005). However, no studies comparing the UK and Portugal were found.

Furthermore, since the researchers are from Portugal it would be easier not only to design the questionnaire in Portuguese, but also to obtain responses. The choice of an English-speaking country to compare with Portugal was desired to make the questionnaire available in English, a language that one of the researchers is also native in.

\subsection{Sample and procedure}

A convenience sampling technique was employed to collect data from Portugal and the UK. Therefore, e-mails were sent to English and Portuguese emails of colleagues, students, personal and professional contacts, International mailing lists (e.g. Trinet) and professional research groups (IFITT and ENTER conference group). In addition, a link with the questionnaire was posted on the researchers' Facebook pages and on Facebook group pages (e.g. Leadership and Strategic Management in Hospitality and Tourism) in late July for 2 weeks. Respondents residing in countries other than Portugal and the UK and those who did not use social media for travel purposes were discarded. The aim was to collect the same number of responses from each country. Yet, since the number of responses from UK was only 83 , a random sample procedure was employed to select also 83 responses from Portuguese respondents. Thus, the final sample is composed by a total of 166 respondents ( 83 from the UK and 83 from Portugal).

Normality tests of the samples were undertaken and revealed that the distribution of the scores of the social media variables was not normally distributed. Therefore, the non-parametric Mann-Whitney test, which is equivalent to the parametric $t$ test of independent samples, was used to test for differences between the two countries. Multivariate Analysis of Variance (MANOVA) analysis was used to ensure that the differences were not due to differences among sample groups' characteristics.

\subsection{Measures}

The questionnaire was originally written in English and proof read by a native English speaking lecturer. Corrections and revisions were made according to her suggestions. To have the questionnaire available in both English and Portuguese, the questionnaire was translated to Portuguese by a Portuguese native speaker, but proficient in the English language. The accuracy of the translation was done by the authors and minor adjustments were made to guarantee that both questionnaires had the same meaning.

The questionnaire was divided into four main sections. At the beginning of the questionnaire, respondents were asked to recall their last trips and select social media websites that they had used to search for travel information. This was a screening question to assure that all respondents used social media for travel purposes. The first section also had a question on the number of times respondents had purchased travel online. 
In the second section, questions pertaining respondents' travel-related behavior were asked. Respondents were asked to recall their trips taken within the last 12 months to answer how many domestic and international trips were taken during that period. The third part of the questionnaire assessed the respondents' use of social media for travel purposes and their level of interest and enjoyment with these websites. Social media use was examined with new measures, but based on literature that has shown that individuals deal with social media by consuming and creating, before, during and after the trip (Cox et al. 2009; Shao 2009; Parra-López et al. 2012). A five point Likert-type scale was applied, with 1 being "Never" and 5 being "Always". Perceived enjoyment with social media was assessed using items developed by Lee et al. (2005), Moon and Kim (2001) and Verhoef and Langerak (2001) with a five point Likert scale, with 1 being "Strongly Disagree" and 5 being "Strongly Agree". Interest in social media was measured with items developed by McQuarrie and Munson (1992), with a five-point differential semantic scale. As opening paragraph was included at the beginning of this section to provide participants with an overview of what was considered social media.

Finally, the last part of the questionnaire contained questions regarding respondents' demographic characteristics, namely age, gender and education level.

\section{Results}

The demographic profile of the respondents by country is presented in Table 2 . The age group with the most significant number of responses, in both countries, was the age group 18-29. The sample seems to be composed by highly educated individuals, with more than $90 \%$ in both countries having at least a college degree.

Table 2 Profile of respondents

\begin{tabular}{lcc}
\hline Characteristic & \multicolumn{2}{l}{ Frequency $(\%)$} \\
\cline { 2 - 3 } & Portuguese & British \\
\hline Age & & \\
$18-29$ & $30(36.1 \%)$ & $27(32.5 \%)$ \\
$30-39$ & $24(28.9 \%)$ & $18(21.7 \%)$ \\
$40-49$ & $18(21.7 \%)$ & $14(16.9 \%)$ \\
$50-59$ & $10(12 \%)$ & $13(15.7 \%)$ \\
Over 60 & $1(1.2 \%)$ & $11(13.3 \%)$ \\
Education & & \\
High school or less & $7(8.4 \%)$ & $2(2.4 \%)$ \\
College degree & $32(38.6 \%)$ & $10(12 \%)$ \\
Master degree & $31(37.3 \%)$ & $39(47 \%)$ \\
Doctoral degree & $13(15.7 \%)$ & $32(38.6 \%)$ \\
Gender & & \\
Male & $24(28.9 \%)$ & $36(43.4 \%)$ \\
Female & $59(71.1 \%)$ & $47(56.6 \%)$ \\
\hline
\end{tabular}


Approximately $39 \%$ of the British have a Doctoral degree, compared to $15.7 \%$ of the Portuguese. In terms of gender, in the Portuguese sample there is a slight skew towards a higher proportion of female participants $(71.1 \%)$.

The Chi-square values and significance levels reported in the last column of Table 3 demonstrate that while there were no significantly differences in the number of domestic trips between travelers from both countries, there were differences in the number of international trips. Over $40 \%$ of the British had taken more than 4 international trips in the past year, while in Portugal only $7.2 \%$ had done so. Another difference between the two countries regards the number of travel purchases online. It was observed that British tend to purchase travel online more often than the Portuguese. In fact, it should be noted that all the British respondents had already purchased travel online at least once, while in the Portuguese sample, $21.7 \%$ had never purchased travel online. According to data from Eurostat (2013), $71 \%$ of individuals from the UK have bought goods or services over the Internet, while in Portugal the percentage only reaches $15 \%$.

TripAdvisor is the most popular social media website in both countries to search for travel information, although much higher in the UK, with $86 \%$ respondents claiming to use this website versus $54 \%$ of the Portuguese respondents. Regarding respondents' use of social media Table 4 shows the mean of the items observed in both countries.

By observing Table 4, it is clear that in both countries social media is predominantly used before travelling and that most social media users are consumers rather than producers, supporting the results obtained in earlier studies

Table 3 Travel behaviors

\begin{tabular}{|c|c|c|c|}
\hline \multirow[t]{2}{*}{ Characteristic } & \multicolumn{2}{|c|}{ Frequency $(\%)$} & \multirow{2}{*}{$\begin{array}{l}\text { Chi-square value } \\
\text { (significance level) }\end{array}$} \\
\hline & Portuguese & British & \\
\hline Number of domestic trips in last year & & & $5.785(0.12)$ \\
\hline 0 & $1(1.2 \%)$ & $8(9.6 \%)$ & \\
\hline 1-3 times & $39(47 \%)$ & $36(43.4 \%)$ & \\
\hline 4-6 times & $18(21.7 \%)$ & $17(20.5 \%)$ & \\
\hline More than 7 & $25(30.1 \%)$ & $22(26.5 \%)$ & \\
\hline Number of International trips in last year & & & $37.785 *(0.00)$ \\
\hline 0 & $29(34.9 \%)$ & $4(4.8 \%)$ & \\
\hline 1-3 times & $48(57.8 \%)$ & $44(53 \%)$ & \\
\hline 4-6 times & $4(4.8 \%)$ & $19(22.9 \%)$ & \\
\hline More than 7 & $2(2.4 \%)$ & $16(19.3 \%)$ & \\
\hline How many times travel purchased online & & & $43.461 *(0.00)$ \\
\hline Never & $18(21.7 \%)$ & $0(0 \%)$ & \\
\hline $1-3$ times & $15(18.1 \%)$ & $5(6 \%)$ & \\
\hline 4-7 times & $18(21.7 \%)$ & $10(12 \%)$ & \\
\hline $8-10$ times & $8(9.6 \%)$ & $5(6 \%)$ & \\
\hline More than 10 times & $24(28.9 \%)$ & $63(76 \%)$ & \\
\hline
\end{tabular}




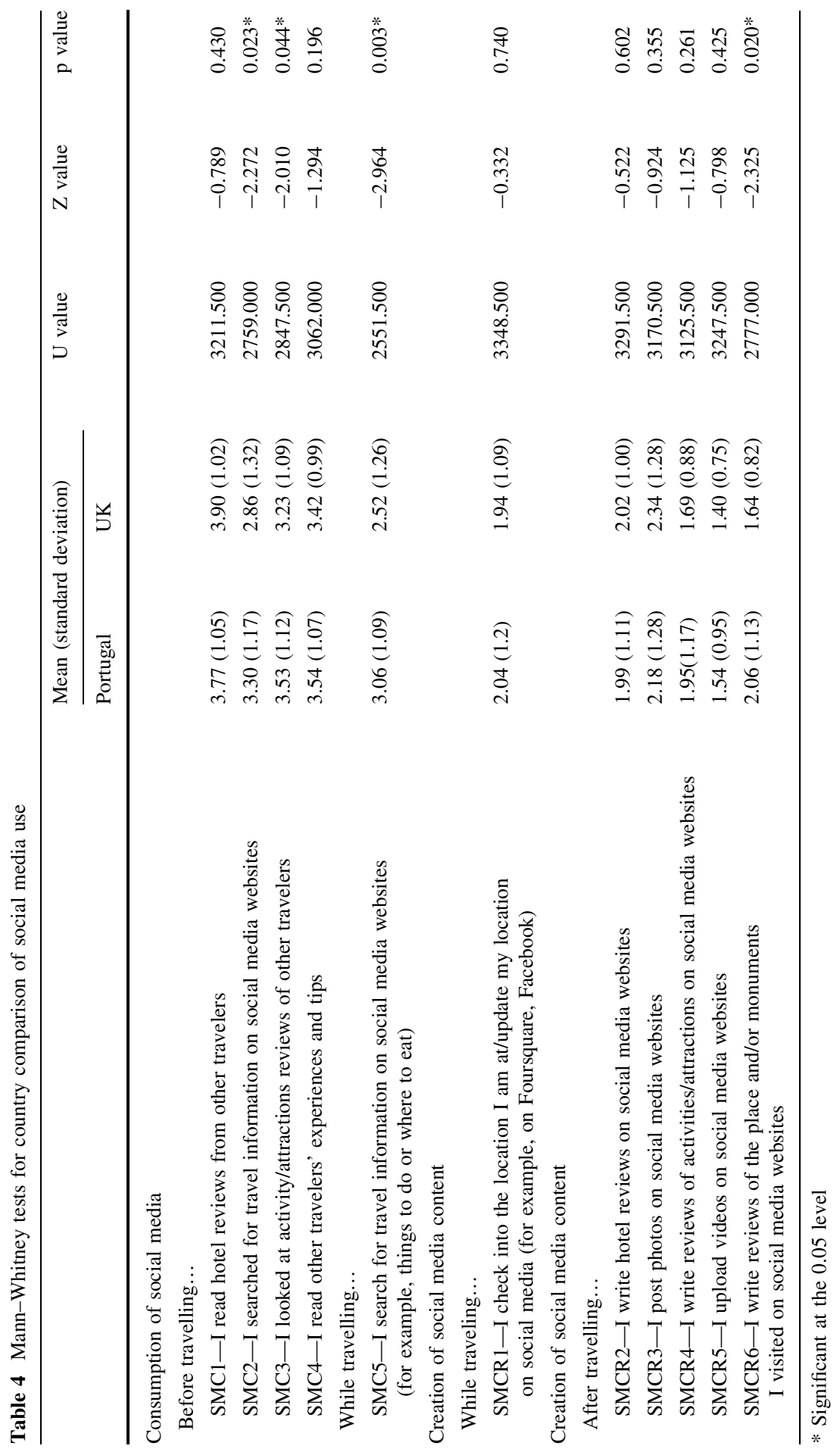


(e.g. Cox et al. 2009; Yoo and Gretzel 2011; Pan and Crotts 2012). One sample $t$ test was used to evaluate statistically significant differences in the Social Media Creation (SMC) items. The results show that while SMC1 mean was not statistically different from 4 in both samples $\left[\mathrm{t}_{\mathrm{uk}}=-0.861 \quad(p=0.392) ; \mathrm{t}_{\mathrm{pt}}=-1.984\right.$ $(p=0.051)]$, the means for all other items were significantly different from 4 , suggesting that the most important activity in both countries before travelling is reading hotel reviews. Therefore, regarding the first research question, the results show that individuals from the different cultures in the current study have similar behavior regarding the time which social media is mostly used for travel planning.

Regarding social media consumption, as the Mann-Whitney results indicate, there is enough evidence to conclude that there are significant differences between the two countries in 3 out of the 5 items (SMC2, SMC3 and SMC5). To validate that Portuguese respondents tend to search for more travel information than the British, before and while travelling a mean score for each case using variables SMC1 though SMC5 was computed and the non-parametric Mann-Whitney exact test was used to assess the differences between Portuguese and British. The results show that, based on the new measure, there is a statistically significant difference in the mean score for Social Media Consumption between Portuguese and British (Mann-Whitney $\mathrm{U}=2817.50, \mathrm{p}=0.042)$. Therefore, addressing our second research question "Does the consumption of social media for travel purposes differ between individuals from different cultures?" the empirical evidence supports that there are differences. The Portuguese tend to rely more on the search of general information before travelling and on the use of social media to search for information on activities and attractions at the destination, both before and while traveling.

Portugal is high on uncertainty avoidance, which deals with a society's tolerance for uncertainty and ambiguity. It indicates to what extent a culture programs its members to feel either uncomfortable or comfortable in unknown and different from usual situations. This might explain Portugal's higher social media consumption levels, to minimize the likelihood of such situations. The results of the current study are comparable with the results of other studies that have found that individuals from countries high on uncertainty avoidance spent more time searching for travel information online (Quintal et al. 2010; Jordan et al. 2013). Moreover, in collectivist cultures, such as Portugal, group values and the opinions of others are considered to be more important (Gretzel et al. 2008; Goodrich and De Mooij 2014). Michopoulou and Moisa (2016) pointed out that China's high contribution and engagement on social media was the reflection of being a collectivist culture. Portugal also has more feminism values which have been found to be positively correlated with opinion seeking (Pornpitakpan 2004). In high power distance cultures, such as Portugal, trustworthiness and the opinions of others are more important (Goodrich and De Mooij 2014) and there is a tendency for higher opinion seeking (Pornpitakpan 2004). Thus, based on the findings of these studies, the cultural dimensions of uncertainty avoidance, collectivism, feminism and power distance may explain why Portugal has higher levels of social media consumption for travel purposes.

In relation to social media creation after travelling, the only significant difference between the two countries is regarding Item SMCR 6 "I write reviews of the place 
and/or monuments I visited on social media websites", which is higher in the Portuguese sample. Portugal is high on collectivism and as Gretzel et al. (2008) point out and other studies have evidenced (e.g. Michopoulou and Moisa 2016), social media websites are more likely to be used in collectivist cultures, since they foster interpersonal exchanges. According to Hofstede's framework the UK is a very individualist country, in which individuals are expected to look after themselves. This may explain their less willing nature to help others by writing reviews as others studies have demonstrated (e.g. Pfeil et al. 2006; Lee and Gretzel 2014). Chinese travelers, form a collectivist culture, are much more likely to engage in cooperative behavior and information sharing than UK travelers (Michopoulou and Moisa 2016). Masculinity versus Femininity dimension may also play a role in explaining this result. Portugal, being low in masculinity, has more cooperative and caring values. Furthermore, societies with a short-term orientation, such as Portugal, have a normative orientation, where people have a strong desire to explain as much as possible. They value the importance of service to others and self-enhancement (Gretzel et al. 2008). However, further studies are necessary to confirm if travelers from collectivist, feminist and short-term oriented cultures are more likely to create online travel content (the third research question), since current results show that if we aggregate the six items of SMCR the differences between the two countries are not statistically significant.

The results given in Table 5 indicate that social media users in both countries consider that using social media for travel purposes can be moderately fun and enjoyable since the mean score for the items are statistically significantly greater than the mid-point of the response scale $\left(\mathrm{t}_{\mathrm{PPSM} 1}=4.323, p=0.000\right.$ and $\left.\mathrm{t}_{\text {PPSM2 }}=2.494, p=0.014\right)$. Web 2.0 has made information search more personalized, active and interactive, which contributes to its hedonic value (Gretzel 2012). In most of the perceived enjoyment items, Portugal has higher values, but the only significant difference is regarding the first item "Using social media for travel purposes is enjoyable" ( $U=2782.500 ; Z=-2.299 ; \mathrm{p}<0.05)$. Research in the American culture with similar scores as the UK regarding individualism, masculinity, uncertainty avoidance and power distance, found that perceived enjoyment had an impact on intentions to use consumer-generated media for travel planning (Ayeh et al. 2013). Considering these findings and the results in our study, culture does not seem to influence the perceived enjoyment of social media use for travel purposes (fourth research question).

Regarding the last research question, if social media interest for travel purposes differs between individuals from different cultures, the results indicate that Portuguese social media users find social media more interesting than the British, with significant differences in items SMI3, SMI4 and SMI5. These results may be a consequence of Portuguese cultural characteristics. Being a friendlier culture, scoring low on masculinity, individualism and pragmatism and high in uncertainty avoidance, the Portuguese see the potential social interaction provided by this type of websites as enjoyable, allowing them to exchange information and feel like they can be useful to aid others in their search for travel information and recommendations. Therefore, the findings suggest that culture may explain the differences in social media interest for travel purposes. 


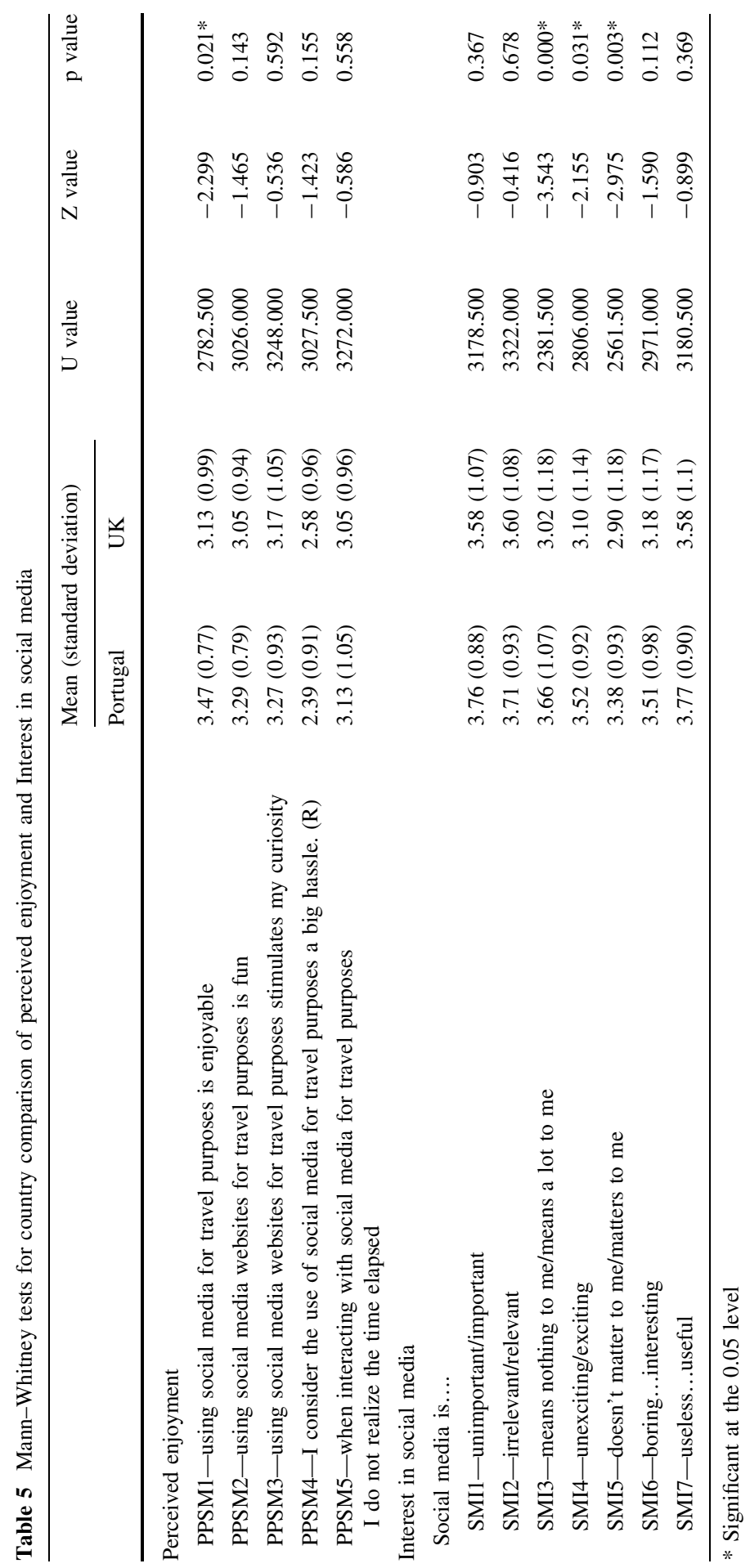


To confirm that the differences are not a consequence of age, gender or education level differences between groups but due to cultural differences, a series of (MANOVA) were conducted using as dependent variables the items related to social media for travel purposes and as factors the country, age, gender and level of education. The results in Table 6 show that in each case only the country (i.e. cultural differences) is significant to explain the differences in traveler's use of social media.

\section{Conclusions and implications}

Recognizing the existence of a research gap in cross-cultural comparisons on social media use for travel purposes, the current study extends previous works underscoring the role of national culture differences in travelers' behavior and perception regarding the use of social media to search and share information before, while and after traveling. This study provides useful insights to travel marketers and providers for understanding traveler's use of social media in different cultures supporting Jackson and Wang (2013) view that online behavior reflects the offline culture of individuals. The results indicate that Hofstede's cultural dimensions explain cross-cultural differences in social media use for travel purposes. Understanding such behavior is crucial to increase the effectiveness of this type of communication since online strategies can be adjusted to country specific situations. It is also a starting point for researchers interested in comparing social media use for travel purposes between different cultures, since there are a limited number of papers addressing this topic.

Considering the use of social media in both countries, the results demonstrate that social media is used during all stages of the travel planning process: before, during and after the trip. However, it is mostly used before the trip, confirming the results obtained by Cox et al. (2009). This finding is important since previous research had reached contradictory results. Since reading hotel reviews is the most important activity of social media use before travelling, hotel managers should pay close attention to reviews of their hotel and respond to both negative and positive reviews. A study conducted by PhoCusWright reinforces this suggestion. The results revealed that $65 \%$ of the respondents would be more likely to book a hotel after seeing hotel management respond to reviews and $85 \%$ said that an appropriate response from the hotel management to a bad review improved their impression of the hotel (TripAdvisor 2015b).

In both countries the use of social media before traveling is high, yet the creation of travel content is low, echoing the conclusions of other studies (e.g. Cox et al. 2009; Yoo and Gretzel 2011; Pan and Crotts 2012). The creation of travel related content is paramount for the success of travel social media websites. Therefore, travel providers and marketers need to create strategies to encourage travelers to create content. Since the main motivations for travel content creation are altruistic sharing, enjoyment and documentation of personal experiences (Gretzel et al. 2011), strategies should focus on these aspects. For example, by reminding travelers how their experiences will help others or by creating online platforms that are 


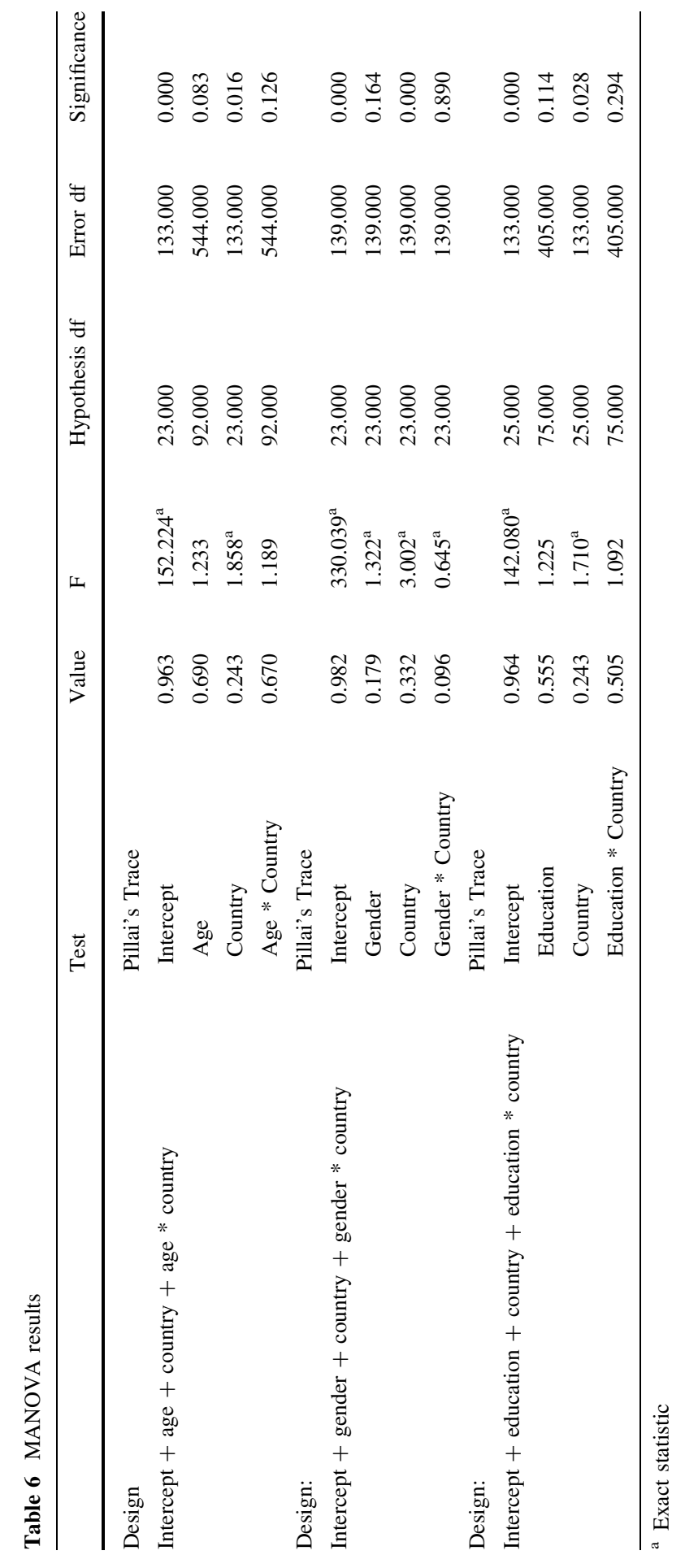


entertaining and where the travel information provided can be stored in a fun and unique way (e.g. by creating a video with pictures posted or creating a virtual trip diary with content created).

This study significantly contributes to the literature by providing evidence of how country-specific differences may impact the use of social media for travel since cross cultural studies addressing social media in the travel context are still scarce. Sia et al. (2009) study further highlights the need to consider cultural differences in online contexts. Although both countries have similarities on the use of social media for travel purposes, there are some significant differences that are explained in this study based on culture, since the effects of other factors (e.g. age, gender and education) were tested and were not significant. In conducting a multiple-country analysis the study provides interesting insights and provides a basis for further research aimed to explain and predict social media use in different countries, based on culture. For instance, collectivist countries, countries high on uncertainty avoidance and with high power distance scores seem to be more likely to consume social media for travel purposes. On the other hand, although no significant differences were found and further researcher is highly desirable, collectivist, feminist and short term oriented countries appear to be more likely to create travel content online.

While more research, in different countries, is needed to confirm these conclusions, it seems logical to expect these relationships. For example, Portuguese travelers, which are high on uncertainty avoidance, tend to use social media websites more than the English before traveling. Therefore, travel marketers and providers aiming to attract travelers high on uncertainty avoidance should invest more in the use of social media and pay close attention to their social media strategies in those countries, as they will be more likely to use social media to search for travel information. On the other hand, collectivist countries are more likely to use social media for purchase decisions than are individualistic cultures (Goodrich and De Mooij 2014). Therefore, it is crucial to provide comprehensive information about travel destinations and services to help reduce uncertainty and to provide accurate information for decision making. Marketers should consider using social media more in collectivistic cultures.

Countries higher in femininity, collectivism and short-term oriented also seem more likely to create content. The practical implication of this study is that travel providers and Destination Marketing Organizations (DMOs) need to be aware that tourists from these countries or countries with similar cultural profiles will be more likely to create content about their travel experience. Therefore, they should adapt some offerings according to the origin of the traveler. They can provide incentives for travelers from specific countries to visit certain attractions, expecting that they will share their experiences and influence others to visit those attractions.

The results of the study indicate that Portuguese respondents consume and create social media more than UK respondents while travelling. This was justified based on cultural differences. However, it should be noted that since UK respondents travel more internationally than the Portuguese respondents, roaming costs might provide a further explanation for this. Even though many hotels and restaurants provide free 
Wi-Fi for international travelers, it would be interesting to further explore if roaming costs are constraining the use of social media during travel.

\section{Limitations and future research}

The major limitation of this study is the sample. The small size and the convenience nature of the sample forces caution in interpreting these results and blocks generalisations of the results. If fact, this study is intended to motivate other researchers to pursue better explanations on how cultural differences influence the use of social media platforms, namely to search for travel information. Replication of the study with bigger samples is highly desirable, even though the statistical procedures carried out can be conducted on small samples.

Another limitation was that it only compared the use of social media between two countries. Future research should replicate this study in other countries with similar cultural scores as Portugal and the UK to compare results. Also, the current research did explore all social influences which, if considered, may affect the results. Indeed, further research is necessary to provide increased confidence regarding the generalizability of the results and to further contribute to clarify the influence of national culture on social media use for travel purposes.

Since enjoyment has been found to be a driver of travel content generated media creation (Yoo and Gretzel 2011), future research could examine this association in both samples. Future research could also investigate the relationship between social media interest with social media consumption and creation.

Finally, research on how to take advantage of cultural differences to maximize the impact and effectiveness of travel related social media websites would also be an interesting research path.

\section{References}

Ayeh JK, Au N, Law R (2013) Predicting the intention to use consumer-generated media for travel planning. Tour Manag 35:132-143. doi:10.1016/j.tourman.2012.06.010

Ayeh JK, Au N, Law R (2016) Investigating cross-national heterogeneity in the adoption of online hotel reviews. Int J Hosp Manag 55:142-153. doi:10.1016/j.ijhm.2016.04.003

Chau PYK, Cole M, Massey AP et al (2002) Cultural differences in the online behavior of consumers. Commun ACM 45:138-143. doi:10.1145/570907.570911

Choi KS, Im I, Hofstede GJ (2016) A cross-cultural comparative analysis of small group collaboration using mobile twitter. Comput Human Behav 65:308-318. doi:10.1016/j.chb.2016.08.043

Chu S-C, Choi SM (2011) Electronic Word-of-Mouth in Social Networking Sites: a Cross-Cultural Study of the United States and China. J Glob Mark 24:263-281. doi:10.1080/08911762.2011.592461

Chung JY, Buhalis D (2008a) Information needs in online social networks. Inf Technol Tour 10:267-281

Chung JY, Buhalis D (2008b) Web 2.0: A study of online travel community. In: Information and communication technologies in tourism, pp 70-81

Cox C, Burgess S, Sellitto C, Buultjens J (2009) The role of user-generated content in tourists' travel planning behavior. J Hosp Mark Manag 18:743-764. doi:10.1080/19368620903235753 
Crotts JC, Erdmann R (2000) Does national culture influence consumers' evaluation of travel services? A test of Hofstede's model of cross-cultural differences. Manag Serv Qual 10:410-419. doi:10.1108/ 09604520010351167

Deloitte (2015) Travel Consumer 2015 engaging the empowered holidaymaker. London

Di Pietro L, Di Virgilio F, Pantano E (2012) Social network for the choice of tourist destination: attitude and behavioural intention. J Hosp Tour Technol 3:60-76. doi:10.1108/17579881211206543

Dimanche F (1994) Cross-cultural tourism marketing research. J Int Consum Mark 6:123-160. doi:10. 1300/J046v06n03_08

Fodness D, Murray B (1997) Tourist information search. Ann Tour Res 24:503-523. doi:10.1016/S01607383(97)00009-1

Fotis J, Buhalis D, Rossides N (2012) Social media use and impact during the holiday travel planning process. In: Fuchs M, Ricci F, Cantoni L (eds) Information and communication technologies in tourism 2012. Springer, Vienna, New York, pp 13-24

Goodrich K, De Mooij M (2014) How "social” are social media? A cross-cultural comparison of online and offline purchase decision influences. J Mark Commun 20:103-116. doi:10.1080/13527266.2013. 797773

Gretzel U (2012) Introduction to the Section on Web 2.0 and Travellers' Behaviour. In: Sigala M, Christou E, Gretzel U (eds) Social media in travel, tourism and hospitality: theory, practice and cases. Ashgate, Surrey, pp 167-169

Gretzel U, Yoo KH (2008) Use and impact of online travel reviews. In: O'Connor P, Höpken W, Gretzel $\mathrm{U}$ (eds) Information and communication technologies in tourism 2008. SpringerWein, Vienna, New York, pp 35-46

Gretzel U, Yoo KH, Purifoy M (2007) Online travel review study: role \& impact of online travel reviews. Lab Intell Syst Tour. doi:10.1300/J052v11n03_03

Gretzel U, Kang M, Lee W (2008) Differences in consumer-generated media adoption and use: a crossnational perspective. J Hosp Mark Manag 17:99-120. doi:10.1080/10507050801978240

Gretzel U, Fesenmaier DR, Lee Y, Tussyadiah I (2011) Narrating travel experiences: The role of new media. In: Sharpley R, Stone PR (eds) Tourist experience: contemporary perspectives. Routledge, New Yourk, pp 171-182

Gursoy D, Umbreit WT (2004) Tourist information search behavior: cross-cultural comparison of European union member states. Int J Hosp Manag 23:55-70. doi:10.1016/j.jhm.2003.07.004

Harris P, Rettie R, Cheung C (2005) Adoption and usage of m-commerce: a cross-cultural comparison of Hong Kong and the United Kingdom. J Electron Commer Res 6:210-224

Hofstede G (1980) Culture's consequences: international differences in work-related values. Sage, Beverly Hills, CA

Hofstede G, Hofstede GJ, Minkov M (2010) Cultures and organizations: software of the mind, 3rd edn. McGraw-Hill Education, New York

Hsu S-Y, Woodside AG, Marshall R (2013) Critical tests of multiple theories of cultures' consequences: comparing the usefulness of models by Hofstede, Inglehart and Baker, Schwartz, Steenkamp, as well as GDP and distance for explaining overseas tourism behavior. J Travel Res 52:679-704. doi:10. $1177 / 0047287512475218$

Huang CY, Chou CJ, Lin PC (2010) Involvement theory in constructing bloggers' intention to purchase travel products. Tour Manag 31:513-526. doi:10.1016/j.tourman.2009.06.003

Jackson LA, Wang J-L (2013) Cultural differences in social networking site use: a comparative study of China and the United States. Comput Human Behav 29:910-921. doi:10.1016/j.chb.2012.11.024

Jacobsen JKS, Munar AM (2012) Tourist information search and destination choice in a digital age. Tour Manag Perspect 1:39-47. doi:10.1016/j.tmp.2011.12.005

Jeng J, Fesenmaier DR (2002) Conceptualizing the travel decision-making hierarchy: a review of recent developments. Tour Anal 7:15-32. doi:10.3727/108354202108749925

Jordan EJ, Norman WC, Vogt CA (2013) A cross-cultural comparison of online travel information search behaviors. Tour Manag Perspect 6:15-22. doi:10.1016/j.tmp.2012.11.002

Kaplan AM, Haenlein M (2010) Users of the world, Unite! Thechallenges and opportunities of Social Media. Bus Horiz 53:59-68

Kim LH, Qu H, Kim DJ (2009) A Study of perceived risk and risk reduction of purchasing air-tickets online. J Travel Tour Mark 26:203-224. doi:10.1080/10548400902925031

Kim Y, Sohn D, Choi SM (2011) Cultural difference in motivations for using social network sites: a comparative study of American and Korean college students. Comput Human Behav 27:365-372. doi:10.1016/j.chb.2010.08.015 
Lee YJ, Gretzel U (2014) Cross-cultural differences in social identity formation through travel blogging. J Travel Tour Mark 31:37-54. doi:10.1080/10548408.2014.861701

Lee MKO, Cheung CMK, Chen Z (2005) Acceptance of Internet-based learning medium: the role of extrinsic and intrinsic motivation. Inf Manag 42:1095-1104

Leung D, Law R, van Hoof H, Buhalis D (2013) Social media in tourism and hospitality: a literature review. J Travel Tour Mark 30:3-22. doi:10.1080/10548408.2013.750919

Li M (2012) Cross-cultural tourist research: a meta-analysis. J Hosp Tour Res 38:40-77. doi:10.1177/ 1096348012442542

Li N, Kirkup G (2007) Gender and cultural differences in Internet use: a study of China and the UK. Comput Educ 48:301-317. doi:10.1016/j.compedu.2005.01.007

Litvin SW, Hoffman LM (2012) Responses to consumer-generated media in the hospitality marketplace: an empirical study. J Vacat Mark 18:135-145. doi:10.1177/1356766712443467

Litvin SW, Crotts JC, Hefner F (2004) Cross-cultural tourist behaviour: a replication and extension involving Hofstede's uncertainty avoidance dimension. Int J Tour Res 6:29-37. doi:10.1002/jtr.468

McQuarrie EF, Munson JM (1992) a revised product involvement inventory: improved usability and validity. Assoc Consum Res 19:108-115 (article)

Michopoulou E, Moisa D (2016) The role of culture on online search behaviour: a comparative study between British and Chinese travellers. Information and communication technologies in tourism 2016. Springer International Publishing, Cham, pp 765-777

Moon JW, Kim YG (2001) Extending the TAM for a World-Wide-Web context. Inf Manag 38:217-230. doi:10.1016/S0378-7206(00)00061-6

Ngai EWT, Tao SSC, Moon KKL (2015) Social media research: theories, constructs, and conceptual frameworks. Int J Inf Manage 35:33-44. doi:10.1016/j.ijinfomgt.2014.09.004

Öz M (2015) Social media utilization of tourists for travel-related purposes. Int J Contemp Hosp Manag 27:1003-1023. doi:10.1108/IJCHM-01-2014-0034

Pan B, Crotts JC (2012) Theoretical models of social media, marketing implications, and future research directions. In: Sigala M, Christou E, Gretzel U (eds) Social media in travel, tourism and hospitality: theory, practice and cases. Ashgate, Surrey, pp 73-83

Parra-López E, Gutiérrez-Taño D, Díaz-Armas RJ, Bulchand-Gidumal J (2012) Travellers 2.0: Motivation, Opportunity and Ability to Use Social Media. In: Sigala M, Christou E, Gretzel U (eds) Social media in travel, tourism and hospitality: theory, practice and cases. Ashgate, Surrey, pp 171-187

Pfeil U, Zaphiris P, Ang CS (2006) Cultural differences in collaborative authoring of wikipedia. J Comput Commun 12:88-113. doi:10.1111/j.1083-6101.2006.00316.x

Phocuswright (2015) Managing global social intelligence. http://www.phocuswright.com/Free-TravelResearch/Managing-Global-Social-Intelligence. Accessed 27 Oct 2016

Pizam A, Jeong G-H (1996) Cross-cultural tourist behavior. Perceptions of Korean tour-guides. Tour Manag 17:277-286. doi:10.1016/0261-5177(96)00019-2

Pookulangara S, Koesler K (2011) Cultural influence on consumers' usage of social networks and its' impact on online purchase intentions. J Retail Consum Serv 18:348-354. doi:10.1016/j.jretconser. 2011.03.003

Pornpitakpan C (2004) Factors associated with opinion seeking. J Glob Mark 17:91-113. doi:10.1300/ J042v17n02_05

Quintal VA, Lee JA, Soutar GN (2010) Tourists' information search: the differential impact of risk and uncertainty avoidance. Int J Tour Res 12:321-333. doi:10.1002/jtr.753

Sabiote-Ortiz CM, Frias-Jamilena DM, Castaneda-Garcia JA (2016) Overall perceived value of a tourism service delivered via different media: a cross-cultural perspective. J Travel Res 55:34-51. doi:10. $1177 / 0047287514535844$

Sakakida Y, Cole ST, Card JA (2004) A cross-cultural study of college students' travel preferences. J Travel Tour Mark 16:35-41. doi:10.1300/J073v16n01_04

Shao G (2009) Understanding the appeal of user-generated media: a uses and gratification perspective. Internet Res 19:7-25. doi:10.1108/10662240910927795

Sia CL, Lim KH, Kwok L et al (2009) Web strategies to promote internet shopping: is culturalCustomization needed? MIS Q 33:491-512

Sparks BA, Browning V (2011) The impact of online reviews on hotel booking intentions and perception of trust. Tour Manag 32:1310-1323. doi:10.1016/j.tourman.2010.12.011

Tham A, Croy G, Mair J (2013) Social media in destination choice: distinctive electronic word-of-mouth dimensions. J Travel Tour Mark 30:144-155. doi:10.1080/10548408.2013.751272 
TripAdvisor (2015a) 6 key travel trends for 2016। TripAdvisor Insights. https://www.tripadvisor.com/ TripAdvisorInsights/n2670/6-key-travel-trends-2016. Accessed 6 Nov 2016

TripAdvisor (2015b) 5 Tips Inspired by Our New Traveler Survey. https://www.tripadvisor.com/ TripAdvisorInsights/n2665/5-tips-inspired-our-new-traveler-survey. Accessed 7 Nov 2016

Verhoef PC, Langerak F (2001) Possible determinants of consumers' adoption of electronic grocery shopping in the Netherlands. J Retail Consum Serv 8:275-285. doi:10.1016/S0969-6989(00)000333

Wang Y, Fesenmaier DR (2004) Modeling participation in an online travel community. J Travel Res 42:261-270. doi:10.1177/0047287503258824

Werthner H, Klein S (1999) Information technology and tourism—a challenging relationship. Vienna, New York

Werthner H, Ricci F (2004) E-Commerce and tourism. Commun Acm 47:101-105. doi:10.1145/1035134. 1035141

Xiang Z, Gretzel U (2010) Role of social media in online travel information search. Tour Manag 31:179-188. doi:10.1016/j.tourman.2009.02.016

Xiang Z, Magnini VP, Fesenmaier DR (2015) Information technology and consumer behavior in travel and tourism: insights from travel planning using the internet. J Retail Consum Serv 22:244-249. doi:10.1016/j.jretconser.2014.08.005

Yoo K-H, Gretzel U (2011) Influence of personality on travel-related consumer-generated media creation. Comput Human Behav 27:609-621. doi:10.1016/j.chb.2010.05.002

Yoo K-H, Gretzel U (2012) Use and Creation of Social Media by Travellers. In: Sigala M, Christou E, Gretzel U (eds) Social media in travel, tourism and hospitality: theory, practice and cases. Ashgate, Surrey, pp 189-205

Zeng B, Gerritsen R (2014) What do we know about social media in tourism? A review. Tour Manag Perspect 10:27-36. doi:10.1016/j.tmp.2014.01.001 